\title{
Autonomic Dysreflexia Severity between Urodynamics and Cystoscopy in Patients with Spinal Cord Injury above T6
}

\author{
Heyi Zhen1, Tianhai Huang2, Xiaoyi Yang2, Qiuling Liu², Qingqing Li², Maping Huang2*, \\ Hui Chen ${ }^{2 *}$
}

${ }^{1}$ Department of Traumatic Brain Injury Rehabilitation, Guangdong Province Work Injury Rehabilitation Hospital, Guangzhou, China

${ }^{2}$ Department of Urology, Guangdong Provincial Work Injury Rehabilitation Hospital, Guangzhou, China

Email: ${ }^{* 149713097 @ q q . c o m, ~ * d o c . c h e n h u i @ 163 . c o m ~}$

How to cite this paper: Zhen, H.Y., Huang, T.H., Yang, X.Y., Liu, Q.L., Li, Q.Q., Huang, M.P. and Chen, H. (2021) Autonomic Dysreflexia Severity between Urodynamics and Cystoscopy in Patients with Spinal Cord Injury above T6. International Journal of Clinical Medicine, 12, 351-356.

https://doi.org/10.4236/ijcm.2021.128031

Received: July 19, 2021

Accepted: August 20, 2021

Published: August 23, 2021

Copyright $\odot 2021$ by author(s) and Scientific Research Publishing Inc. This work is licensed under the Creative Commons Attribution International License (CC BY 4.0).

http://creativecommons.org/licenses/by/4.0/

\begin{abstract}
Objective: The objective is to evaluate autonomic dysreflexia (AD) severity between urodynamics and cystoscopy in patients with spinal cord injury (SCI) above thoracic 6 (T6). Design: It is a cross-sectional survey. Subject and methods: The study was carried out in 22 patients with SCI above T6 who underwent both procedures of urodynamics and cystoscopy; all patients developed episodes of AD. The systolic blood pressure (SBP) and diastolic blood pressure (DBP) were measured and recorded at the beginning and during the various stages of the two examinations. $\mathrm{AD}$ was defined as a rise in SBP above $20 \mathrm{~mm}$ Hg. Results: There was no significant difference in SBP and DBP at baseline before urodynamics and cystoscopy. Both urodynamics and cystoscopy triggered episodes of AD. The volume of water instilled during cystoscopy was typically standard and smaller $(150 \mathrm{~mL})$ in comparison with urodynamics, where volume varied depending on cystometric bladder capacity (the mean bladder volume in our study was $234.86 \pm 139.06 \mathrm{~mL}$ ). The SBP was significantly different between cystoscopy and urodynamics $(49.23 \pm 23.07 \mathrm{~mm} \mathrm{Hg}$ and $35.14 \pm 15.75 \mathrm{~mm} \mathrm{Hg}$, respectively; $\mathrm{P}=0.023)$. Conclusions: Although bladder distension during cystoscopy was less than that in urodynamics, the severity of $\mathrm{AD}$ was more pronounced during cystoscopy. It is recommended that monitoring of cardiovascular parameters during these procedures should be routinely performed.
\end{abstract}

\section{Keywords}

Autonomic Dysreflexi, Spinal Cord Injury, Urodynamics, Cystoscopy 


\section{Introduction}

Spinal cord injury (SCI) is a significant cause of morbidity and mortality in developed nations, with a global annual incidence of 1:25,000 [1] [2]. Bladder dysfunction and autonomic dysreflexia (AD) are common outcomes of cervical and high thoracic SCI. AD is clinically defined as an elevation in systolic blood pressure $(\mathrm{SBP}) \geq 20 \mathrm{~mm} \mathrm{Hg}$ from baseline in response to noxious or innocuous stimuli below injury level [3]. It is an acute disease with symptoms ranging from mild, such as headache, sweating, hot flashes, piloerection, and anxiety, to severe [4] [5] [6] [7] [8], such as arrhythmia, including atrial fibrillation, and high SBP above $300 \mathrm{mmHg}$, which may lead not only to cerebral hemorrhage but also to convulsions and death [9] [10] [11]. Several stimuli can lead to AD, but the most common triggering factor is bladder distension, which accounts for up to $85 \%$ of cases [12]. The commonest urological procedures that can lead to $\mathrm{AD}$ are cystoscopy and urodynamics, secondary to bladder filling. The risk of inducing AD has been shown to be reduced with flexible cystoscopy in a cohort of six of 39 patients who had previously had AD during rigid cystoscopy [13] [14]. Considering the differences in the technique of cystoscopy and urodynamics, including the filling rate and method of filling, the severity of $\mathrm{AD}$ might be also difference between these two procedures. In this study, we evaluate the severity of AD in individuals with SCI at or above thoracic 6 (T6) level performed both urological procedures of urodynamics and cystoscopy.

\section{Materials and Methods}

A total of 22 consecutive patients with SCI at or above the T6 neurological level underwent both urodynamic and cystoscopic examinations during a 1-year period were screen. Only individuals who developed episodes of $\mathrm{AD}$ were selected included into this study. Exclusion criteria were the presence of additional neurological disorder or history of cardiovascular or genitourinary system disorder. The sex, age, duration of injury, the SCI level and class according to the American Spinal Cord Injury Association (ASIA) Impairment Scale (AIS) classification of the patients were recorded.

The urodynamics examination was performed following the standards of the International Continence Society. The examination consisted of cystometry with warm sterile water $\left(37.1^{\circ} \mathrm{C}\right)$ filled at a fixed $30 \mathrm{~mL}$ per minute rate through a pump to a double lumen catheter (6 Fr, Laborie,) while patients were supine. Abdominal pressure was measured with an intrarectal balloon catheter (10 Fr, Laborie). Filling was stopped when the patient subjectively reported the sensation of fullness, urine leakage occurred or bladder filling reached $400 \mathrm{~mL}$.

Cystoscopy was conducted with the patient in a lithotomy position; $150 \mathrm{~mL}$ of warm sterile water $\left(37.1^{\circ} \mathrm{C}\right)$ were instilled into the bladder. The filling rate varied from 30 to $50 \mathrm{~mL}$ per minute through gravity filling while a rigid cystoscope was introduced into the urethra. When the scope entered the bladder, a systematic inspection of the bladder mucosa was carried out. Once cystoscopy was completed, the scope was withdrawn and bladder was emptied. 
Before both of the two procedures, $10 \mathrm{~mL}$ of $2 \%$ lidocaine jelly was introduced intra-urethrally. The systolic blood pressure (SBP) and diastolic blood pressure (DBP) were measured and recorded at the beginning and every 1minute infused during urodynamic and cystoscopic examinations. $\mathrm{AD}$ was defined as a rise in SBP above $20 \mathrm{~mm} \mathrm{Hg}$.

Statistical analysis Statistical analyses were performed by using SPSS 13.0 software (SPSS Inc., Chicago, IL, USA). The paired t test was used in the comparison of filling beginning and end SBP, DBP values of the patients. A P-value below 0.05 was considered statistically significant.

\section{Results}

Demographic and clinical features of the patients in the study were presented in Table 1 . The mean age was $40.73 \pm 14.43$ years, mean injury duration $1.05 \pm$ 1.60 years. Of the 22 patients, $16(72.7 \%)$ were cervical and $6(27.3 \%)$ were thoracic. The distribution of the American Spinal Injury Association Impairment Scale (AIS) scores were: 12 (54.5\%) Grade A, 3 (13.6\%) Grade B, 6 (27.3\%) Grade C and 1 (4.5\%) Grade D.

Table 2 displays the SBP, DBP at baseline and changes during the urodynamics and cystoscopy. SBP and DBP at baseline before the two examinations were similar in these individuals. Both urodynamics and cystoscopy triggered episodes of $\mathrm{AD}$. The volume of water instilled during cystoscopy was typically standard and smaller $(150 \mathrm{~mL})$ in comparison with urodynamics, where volume varied depending on bladder capacity (the mean bladder volume in our study was $234.86 \pm 139.06 \mathrm{~mL}$ ). The SBP change were significantly different between cystoscopy and urodynamics (49.52 $\pm 23.07 \mathrm{~mm} \mathrm{Hg}$ and $35.14 \pm 15.75 \mathrm{~mm} \mathrm{Hg}$ respectively; $\mathrm{P}=0.023)$. Though $\mathrm{DBP}$ increase during $\mathrm{AD}$, there are no different change between cystoscopy and urodynamics $(\mathrm{P}=0.052)$.

Table 1. The demographic and clinical features of the patients in the study.

\begin{tabular}{cc}
\hline Variables & $\mathrm{n}=22$ \\
\hline Age, year & \\
Mean \pm SD & $40.73 \pm 14.43$ \\
\hline Sex, N (\%) & $21(95.5 \%)$ \\
Male & $1(4.5 \%)$ \\
Femal & \\
\hline Disease duration, year & $1.05 \pm 1.60$ \\
Mean \pm SD & \\
\hline Level of spinl cord injury, N (\%) & $16(72.7 \%)$ \\
Cervical & $6(27.3 \%)$ \\
Thoracic & \\
\hline AIS grade, N (\%) & $12(54.5 \%)$ \\
A & $3(13.6 \%)$ \\
B & $6(27.3 \%)$ \\
C & $1(4.5 \%)$ \\
\hline D &
\end{tabular}

SD: standard deviation; SCI: spinal cord injury; AIS: American spinal injury association impairment scale. 
Table 2. The SBP, DBP at baseline and changes during the urodynamics and cystoscopy.

\begin{tabular}{cccc}
\hline & Urodynamics & Cystoscopy & P-value \\
\hline SBP baseline $(\mathrm{mm} \mathrm{Hg})$ & $109.09 \pm 8.76$ & $109.27 \pm 9.19$ & 0.947 \\
SBP changes $(\mathrm{mm} \mathrm{Hg})$ & $35.14 \pm 15.75$ & $49.23 \pm 23.07$ & 0.023 \\
DBP baseline $(\mathrm{mm} \mathrm{Hg})$ & $69.77 \pm 7.43$ & $69.95 \pm 7.61$ & 0.936 \\
DBP changes $(\mathrm{mm} \mathrm{Hg})$ & $16.95 \pm 9.579$ & $23.41 \pm 11.68$ & 0.052 \\
\hline
\end{tabular}

SBP: systolic blood pressure; DBP: diastolic blood pressure.

\section{Discussion}

$\mathrm{AD}$ might not been aware well by the physicians and healthcare professionals who were outside of specialist spinal injury centres, leading to delays in treatment and potentially life-threatening consequences for patients [15]. Especially some patients might not be aware of being at risk [16] as AD can occur asymptomatically, also known as silent $\mathrm{AD}$, i.e., without any clinical symptoms. Neurogenic lower urinary tract dysfunction (NLUTD) is a common consequence after SCI [17]. As stimuli from the lower urinary tract are the most common causes of $\mathrm{AD}$, reportedly in $75 \%$ - $85 \%$ of cases [12]. Urodynamic investigation is the gold standard to evaluate lower urinary tract function and routine urodynamic study of SCI patients is crucial for clinical decision making [18] [19]. Cystoscopy is not only a normal inspection for NLUTD, but also is required when performed the treatment of bladder stone or Botulinum Toxin A bladder injection.

In our study though the volume of water instilled during cystoscopy was smaller in comparison with urodynamics, the increase in SBP during cystoscopy was signifificantly higher than urodynamics. Differences in the technique of each procedure, including the filling rate and method of filling, could be one reason explain the difference in severity of $\mathrm{AD}$ between cystoscopy and urodynamics. Other stimuli in addition to bladder distention might also be contributing to the development of $\mathrm{AD}$ during cystoscopy, such as urethral stimulation during cystoscopy [20]. The physiology of urethral afferents was different from bladder, it could be excited by low-threshold mechanical stimulation induced by movements of a urethral catheter, but not respond sensitive to bladder distension [21]. In our study when perform cystoscopy we uses a rigid cystoscope (21 Fr) which was larger in size than catheters required for urodynamics (6 Fr). So cystoscopy includes greater stimulation of the urethra and bladder neck afferents during the procedure through urethral/prostate/internal sphincter passage and dilation, which could then provides more intense afferent stimulation to the spinal cord and trigger more pronounced episodes of AD.

$\mathrm{AD}$ is a diagnosis of which all health professionals interacting with patients with SCI should be aware. In particular, as the commonest cause is genitourinary, the urologist should also be particularly careful whilst investigating patients with SCI. 


\section{Conclusion}

Although bladder distension during cystoscopy was less than that in urodynamics, the severity of $\mathrm{AD}$ was more pronounced during cystoscopy. It is recommended that monitoring of cardiovascular parameters during these procedures should be routinely performed.

\section{Funding}

This study was supported by: Medical Scientific Research Foundation of Guangdong Province, China (grant number A2021221). Traditional Chinese Medicine of Guangdong Province, China (grant number 20212034).

\section{Conflicts of Interest}

The authors declare no conflicts of interest regarding the publication of this paper.

\section{References}

[1] Sekhon, L.H. and Fehlings, M.G. (2001) Epidemiology, Demographics, and Pathophysiology of Acute Spinal Cord Injury. Spine (Phila Pa 1976), 26, S2-S12

[2] Anderson, K.D. (2004) Targeting Recovery: Priorities of the Spinal Cord-Injured Population. Journal of Neurotrauma, 21, 1371-1383. https://doi.org/10.1089/neu.2004.21.1371

[3] Mathias, C.J. and Bannister, R. (2002) Autonomic Disturbances in Spinal Cord Lesions. In: Bannister, R. and Mathias, C.J., Eds., Autonomic Failure: A Textbook of Clinical Disorders of the Autonomic Nervous System, Oxford University Press, New York, 839-881.

[4] Yarkony, G.M., Katz, R.T. and Wu, Y.C. (1986) Seizures Secondary to Autonomic Dysreflexia. Physical Medicine and Rehabilitation, 67, 834-835.

[5] Pine, Z.M., Miller, S.D. and Alonso, J.A. (1991) Atrial Fibrillation Associated with Autonomic Dysreflexia. American Journal of Physical Medicine \& Rehabilitation, 70, 271-273.

[6] Eltorai, I., Kim, R., Vulpe, M., Kasravi, H. and Ho, W. (1992) Fatal Cerebral Hemorrhage Due to Autonomic Dysreflexia in a Tetraplegic Patient: Case Report and Review. Paraplegia, 30, 355-360.

[7] Vallès, M., Benito, J., Portell, E. and Vidal, J. (2005) Cerebral Hemorrhage Due to Autonomic Dysreflexia in a Spinal Cord Injury Patient. Spinal Cord, 43, 738-740.

[8] Dolinak, D. and Balraj, E. (2007) Autonomic Dysreflexia and Sudden Death in People with Traumatic Spinal Cord Injury. The American Journal of Forensic Medicine and Pathology, 28, 95-98.

[9] Mathias, C.J. and Bannister, R. (2002) Autonomic Disturbances in Spinal Cord Lesions. In: Mathias D.J., Ed., Autonomic Failure: A Textbook of Clinical Disorders of the Autonomic Nervous System, Oxford University Press, Oxford, 839-881.

[10] Linsenmeyer, T.A., Campagnolo, D.I. and Chou, I.H. (1996) Silent Autonomic Dysreflexia during Voiding in Men with Spinal Cord Injuries. The Journal of Urology, 155, 519-522.

[11] Ekland, M., Krassioukov, A., McBride, K.E. and Elliott, S.L. (2007) Incidence of Autonomic Dysreflexia and Silent Autonomic Dysreflexia in Men with SCI Under- 
going Sperm Retrievel: Implications for Clinical Practice. The Journal of Spinal Cord Medicine, 30, 43-50.

[12] Gunduz, H. and Binak, D.F. (2012) Autonomic Dysreflflexia: An Important Cardiovascular Complication in Spinal Cord Injury Patients. Cardiology Journal, 19, 215-219. https://doi.org/10.5603/CJ.2012.0040

[13] Chancellor, M.B., Rivas, D.A., Erhard, M.J., Hirsch, I.H. and Bagley, D.H. (1993) Flexible Cystoscopy during Urodynamic Evaluation of Spinal Cord-Injured Patients. Journal of Endourology, 7, 531-535. https://doi.org/10.1089/end.1993.7.531

[14] Chancellor, M.B. and Kiiholma, P. (1992) Urodynamic Evaluation of Patients Following Spinal Cord Injury. Seminars in Urology, 10, 83-94.

[15] Krassioukov, A., Tomasone, J.R., Pak, M., Craven, B.C., Ghotbi, M.H., Ethans, K., Martin Ginis, K.A., Ford, M. and Krassioukov-Enns, D. (2016) “The ABCs of AD”: A Prospective Evaluation of the Efficacy of an Educational Intervention to Increase Knowledge of Autonomic Dysreflexia Management among Emergency Health Care Professionals. The Journal of Spinal Cord Medicine, 39, 190-196.

https://doi.org/10.1179/2045772315Y.0000000037

[16] Linsenmeyer, T.A., Campagnolo, D.I. and Chou, I.H. (1996) Silent Autonomic Dysreflexia during Voiding in Men with Spinal Cord Injuries. Journal of Urology, 155, 519-522. https://doi.org/10.1097/00005392-199602000-00030

[17] Ruffion, A., et al. (2013) Systematic Review of the Epidemiology of Urinary Incontinence and Detrusor Overactivity among Patients with Neurogenic Overactive Bladder. Neuroepidemiology, 41,146-155. https://doi.org/10.1159/000353274

[18] Linsenmeyer, T.A. and Linsenmeyer, M.A. (2013) Impact of Annual Urodynamic Evaluations on Guiding Bladder Management in Individuals with Spinal Cord Injuries. The Journal of Spinal Cord Medicine, 36, 420-426.

[19] Blok, B., et al. (2015) EAU Guidelines on Neuro-Urology. http://uroweb.org/guideline/neuro-urology/

[20] Liu, N., Fougere, R., Zhou, M.W., et al. (2013) Autonomic Dysreflflexia Severity during Urodynamics and Cystoscopy in Individuals with Spinal Cord Injury. Spinal Cord, 51, 863-867.

[21] DeGroat, W.C. and Yoshimura, N. (2009) Afferent Nerve Regulation of Bladder Function in Health and Disease. In: Brendan, J.C. and Domenico, S., Ed., Handbook of Experimental Pharmacology, Springer, Berlin, 91-138.

https://doi.org/10.1007/978-3-540-79090-7_4 